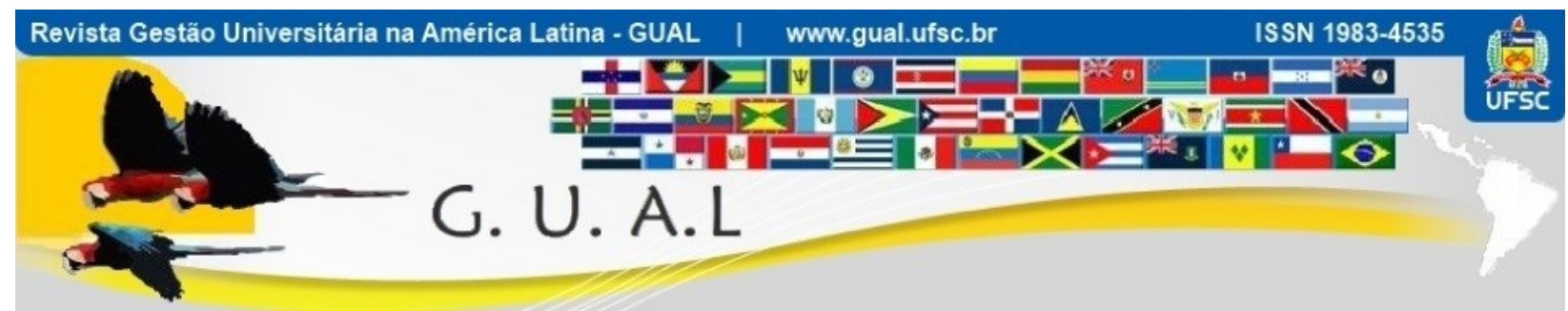

DOI: http://dx.doi.org/10.5007/1983-4535.2016v9n2p70

\title{
DESENVOLVIMENTO DO ENSINO DE ESTRATÉGIA EM CURSOS DE GRADUAÇÃO EM ADMINISTRAÇÃO DE INSTITUIÇÕES DE ENSINO SUPERIOR PELA PERSPECTIVA DE PROFESSORES E ALUNOS
}

\section{TEACHING STRATEGY DEVELOPMENT IN UNDERGRADUATE COURSES IN MANAGEMENT OF HIGHER EDUCATION INSTITUTIONS FROM THE PERSPECTIVE OF TEACHERS AND STUDENTS}

Eduardo Guedes Villar, Doutorando Universidade Federal do Paraná - UFPR eduardogvillar@gmail.com

Silvana Anita Walter, Doutora Universidade Estadual do Oeste do Paraná - UNIOESTE silvanaanita.walter@gmail.com

Recebido em 29/junho/2014

Aprovado em 25/janeiro/2016

Sistema de Avaliação: Double Blind Review

Esta obra está sob uma Licença Creative Commons Atribuição-Uso. 


\title{
RESUMO
}

Este estudo objetivou analisar o desenvolvimento do ensino de estratégia em cursos de graduação em Administração de IES do Vale do Itajaí pela perspectiva de professores e de alunos. Revisam-se estudos sobre abordagens de estratégias, métodos e técnicas de ensino de estratégia e os papéis dos professores de estratégia. Realizou-se uma pesquisa qualitativa por meio de um estudo de caso coletivo com estudantes (grupos de foco) e professores (entrevistas em profundidade) de uma instituição privada e uma pública, além de pesquisa documental. Quanto ao corpo de conhecimento em estratégia, identificou-se a presença das abordagens clássicas. Ambas as IES trabalham com livros de autores clássicos nacionais e internacionais. Sobre os métodos pedagógicos, a IES "A" utiliza a interação entre a teoria de planejamento estratégico e a aplicação em uma empresa, enquanto a IES "B" privilegia as discussões teóricas. Quanto à tipificação de condutas, percebeu-se um padrão de ação dos professores no que tange à cobrança de leitura e à pontualidade na entrega de atividades. Os indivíduos (professores de estratégia) possuem ações específicas, sendo que essas ações são tipificadas como formas de ação, ou seja, padrões coletivamente objetivados de ensinar, de repassar ou de difundir o conhecimento de estratégia.

Palavras-chave: Ensino de estratégia. Graduação em administração. Instituições de ensino superior. Professores. Alunos.

\begin{abstract}
This study aimed to analyze the teaching strategy development in undergraduate courses in HEI Management of Itajaí Valley from the perspective of students and teachers. Studies of strategy approaches have been reviewed, as well as methods and techniques of teaching strategy and the role of strategy teachers. A qualitative research has been performed based on a collective case study with students (focus groups) and teachers (in depth interviews) of a private and a public institution, in addition to a documentary research. Regarding the body of knowledge in strategy, it has been identified the presence of classical approaches. Both HEI use books from national and international classic authors. In relation to teaching methods, the HEI "A" uses the interaction between the theory of strategic planning and the application in a company, whereas the HEI " $B$ " gives preference to theoretical discussions. Regarding the typification of conduct, it has been noticed a pattern of action of teachers regarding the collection of reading and on-time delivery of activities. The individuals (strategy teachers) have specific actions, which are typified as forms of action, i.e. patterns collectively targeted to teach, to impart or disseminate knowledge of strategy.
\end{abstract}

Keywords: Teaching strategy. Graduation in management. Higher education institutions. Teachers. Students. 


\section{DESENVOLVIMENTO DO ENSINO DE ESTRATÉGIA EM CURSOS DE GRADUAÇÃO EM \\ ADMINISTRAÇÃO DE INSTITUIÇÕES DE ENSINO SUPERIOR PELA PERSPECTIVA DE \\ PROFESSORES E ALUNOS \\ DOI: http://dx.doi.org/10.5007/1983-4535.2016v9n2p70}

\section{INTRODUÇÃO}

Os primeiros cursos de Administração de Negócios surgiram nos séculos XIX e XX, nas escolas de Wharton e Harvard, nos Estados Unidos, mais especificamente com a criação, em 1912, da cadeira Política de Negócios. Tal disciplina era ministrada na fase final do curso e fundamentalmente trabalhava a administração de maneira funcional (VIZEU; GONÇALVES, 2010).

Em solo brasileiro, de acordo com Bertero et al. (2003), o ensino de estratégia iniciou nas décadas de 1960 e 1970, com nomenclaturas diferenciadas, como Política de Negócios e Diretrizes Administrativas. Tais disciplinas eram empregadas e aplicadas constantemente devido ao crescimento econômico (empresas privadas e estatais), ao aumento de subsidiárias multinacionais, às privatizações, concessões e fusões de empresas nacionais e estrangeiras, a fim de enfrentar a concorrência global (NICOLINI, 2003).

Quanto à abordagem pedagógica de estratégia, Bertero et al. (2003) afirmam que não existia uma sistematização do conteúdo, tampouco uma estruturação teórico-formal, pressupondo-se que o trabalho com estudos de casos sucessivos implicaria na formação de uma "mentalidade estratégica" e introduziria o aluno no mundo organizacional.

Em um segundo momento, na década de 1990, segundo Bertero et al. (2003), surgiu a gestão estratégica, que diminuiu o foco no planejamento. A estratégia deixou de estar restrita a uma equipe ou departamento específico de formulação estratégica e passou a ser responsabilidade de todos na organização. Essas teorias, para Bertero et al. (2003), apesar de serem da década de 1980, foram exploradas tardiamente no Brasil, ou seja, em meados da década de 1990. Assim, apesar das críticas, o modelo de posicionamento ainda predomina na área de gestão estratégica no país, fruto da possibilidade de aplicação, nas organizações, do modelo de Porter.

A forte influência norte-americana estabelecida nos primórdios da instalação dessa área de conhecimento dirigiu o desenvolvimento de toda a área de Administração no Brasil. Segundo Nicolini (2003), o ensino de graduação consolidou-se como forma de transferência tecnológica e de conhecimentos técnicos, desvinculando-se das atividades de ensino e pesquisa. Para o autor, essa importação de conhecimento fez com que o mesmo fosse construído em condições econômicas, sociais e culturais diferentes da realidade brasileira, 


\section{DESENVOLVIMENTO DO ENSINO DE ESTRATÉGIA EM CURSOS DE GRADUAÇÃO EM \\ ADMINISTRAÇÃO DE INSTITUIÇÕES DE ENSINO SUPERIOR PELA PERSPECTIVA DE PROFESSORES E ALUNOS \\ DOI: http://dx.doi.org/10.5007/1983-4535.2016v9n2p70}

bem como dirigiu o país a uma dependência intelectual, que não conseguiu ser solucionada e que ainda se reflete no cenário atual.

Outro aspecto a ser apontado é que, no Brasil, pouco tem sido pesquisado e estudado sobre o processo de desenvolvimento do conhecimento em estratégia. Destaca-se, portanto, nesse sentido, a importância de apreender como o conhecimento em estratégia é repassado e interpretado por professores e alunos, o que pode contribuir para a própria compreensão dessa área de conhecimento.

A partir do exposto, realizou-se esta pesquisa, a qual buscou responder à seguinte pergunta: Como ocorre o ensino de estratégia em cursos de graduação em Administração de Instituições de Ensino Superior (IES) do Vale do Itajaí, Santa Catarina? Como propósito de pesquisa, objetivou-se analisar o desenvolvimento do ensino de estratégia em cursos de graduação em Administração de IES do Vale do Itajaí pela perspectiva de professores e de alunos. Os objetivos específicos que sustentaram tal intenção foram: a) verificar conceitos, abordagens e teorias empregadas nas disciplinas de estratégia; b) evidenciar os métodos e as técnicas pedagógicas aplicados ao ensino de estratégia; e c) compreender o papel do professor relacionando-o a rotinas, condutas e comportamentos.

A pesquisa realizada encontra-se exposta neste artigo, que, além desta primeira parte introdutória, traz, na segunda seção, a revisão de literatura, com as principais abordagens e conceitos da área, o ensino de estratégia, os métodos e técnicas pedagógicas e o papel do docente e do discente em sala de aula; na terceira, o delineamento metodológico utilizado para a realização desta pesquisa de casos coletivos; na quarta, a análise e a interpretação dos principais resultados da pesquisa; e, por fim, na quinta e última seção, as considerações finais, com o intuito de solucionar a pergunta de pesquisa e apresentar as limitações e sugestões para pesquisas futuras.

\section{FUNDAMENTAÇÃO TEÓRICA}

Nesta seção, revisam-se estudos sobre abordagens de estratégias, métodos e técnicas de ensino de estratégia e os papéis dos professores de estratégia.

\subsection{ABORDAGENS DE ESTRATÉGIA}

Entende-se que, independente do segmento em que atua, uma organização, para sua sobrevivência, prosperidade e alcance dos objetivos, necessita, de estratégias, apesar de não 


\section{DESENVOLVIMENTO DO ENSINO DE ESTRATÉGIA EM CURSOS DE GRADUAÇÃO EM \\ ADMINISTRAÇÃO DE INSTITUIÇÕES DE ENSINO SUPERIOR PELA PERSPECTIVA DE PROFESSORES E ALUNOS \\ DOI: http://dx.doi.org/10.5007/1983-4535.2016v9n2p70}

haver consenso nos conceitos utilizados por diferentes autores. Whittington (2002) indica que conceituar estratégia não é tarefa fácil, uma vez que, se houvesse facilidade, não existiria dissenso entre consultores e teóricos a respeito disso. Para organizar os múltiplos entendimentos sobre estratégia, Whittington (2002) apresenta quatro abordagens: a clássica, a evolucionária, a processual e a sistêmica.

A abordagem clássica que, de acordo com Whittington (2002), é a mais antiga e influente entre as vertentes de estratégias, conta com métodos de planejamento racional para o alcance dos objetivos, além de que busca a lucratividade do negócio. Os maiores defensores dessa abordagem são Chandler, Sloan, Porter, Andrews e Ansoff, os quais, a partir de suas ideias econômicas perante o planejamento racional e sobre as expectativas militaristas, indicam o comando hierárquico como a representação do pensamento clássico sobre formulação e implementação da estratégia.

Segundo Ansoff (1965), as estratégias eram formadas pelo alto escalão das organizações, as quais repassavam para as gerências suas respectivas responsabilidades de forma desmistificada, detalhando as tarefas a serem executadas pelos mais baixos níveis hierárquicos. Para Chandler (1962), a estratégia é uma visão dos objetivos organizacionais em longo prazo, com concepção explícita e deliberada das metas e da viabilização de ações e recursos para atingir os melhores resultados. Nesse sentido, a estratégia molda a estrutura da organização e o modo de administrá-la.

Quanto à abordagem evolucionária em estratégia, Whittington (2002) menciona a existência de menos confiança na habilidade da gerência em planejar e agir racionalmente, ou seja, os gerentes esperam que os mercados garantam a maximização dos lucros diante da ocorrência de um processo natural de seleção pelo ambiente. Teóricos defensores dessa abordagem apontam que sobreviverão os gerentes que se adequarem de forma mais competente ao meio do qual fazem parte (ambiente dos negócios) (WHITTINGTON, 2002). Esse mesmo autor considera exemplos de publicações nessa perspectiva: "The population ecology of organizations", de Hannan e Freemann (1977), e a Teoria dos Custos de Transação, de Williamson (1991).

Por sua vez, a abordagem processual, de forma geral, concorda com a teoria evolucionista quanto ao desabono do desenvolvimento racional de estratégia, considerando fútil e imperfeito o planejamento a longo prazo. No entanto, confia menos na força dos mercados ou do ambiente para maximizar os resultados de uma organização 


\section{DESENVOLVIMENTO DO ENSINO DE ESTRATÉGIA EM CURSOS DE GRADUAÇÃO EM \\ ADMINISTRAÇÃO DE INSTITUIÇÕES DE ENSINO SUPERIOR PELA PERSPECTIVA DE PROFESSORES E ALUNOS \\ DOI: http://dx.doi.org/10.5007/1983-4535.2016v9n2p70}

(WHITTINGTON, 2002). Igualmente considera de fundamental importância as complexidades internas de uma organização, apontando que o ser humano é apenas limitadamente racional (Cyert e March, 1963) e que a estratégia emerge do aprendizado da organização (MINTZBERG et al., 2000). Assim, a estratégia é formulada por meio de um processo adaptável, contínuo e com pequenas mudanças adicionais, além de eminentemente político (MINTZBERG et al., 2006).

Já, para a abordagem sistêmica, a estratégia é relativista, uma vez que varia conforme a cultura, o contexto e as relações sociais de cada região ou país. Seu princípio central não está relacionado simplesmente aos indivíduos de forma imparcial, calculista e econômica, mas profundamente enraizado em sistemas sociais entrelaçados. Defende, da mesma forma, que não há uma única meta almejada pelos estrategistas sistêmicos, assim como não há uma única forma de alcançar essa meta, pois, de acordo com o contexto, emergirão objetivos e processos diferentes associados a variáveis como classes sociais, profissões, nações, estados, famílias e gêneros. Nesse sentido, os sistêmicos consideram a racionalidade e a maximização do lucro como fundamentais, desde que sejam alcançados em uma cultura específica em que estão inseridas (WHITTINGTON, 2002). Whittington (2002) cita Granovetter (1985) e Whitley (1999) como alguns estudiosos importantes dessa perspectiva.

\subsection{O ENSINO DE ESTRATÉGIA}

No ensino de estratégia, a primeira abordagem pedagógica utilizada foi o método de caso, na Escola de Direito de Harvard, no início dos anos de 1990, o qual, logo após, migrou para a área de negócios em Administração. Primeiramente, executivos locais eram convidados a participar das aulas e a apresentar problemas de suas organizações, que eram discutidos entre os alunos, os quais propunham soluções. No final da década de 1940, uma série de casos de ensino foi organizada por George Albert Smith e Roland Christensen, professores da Escola de Negócios, de Harvard, do que se originou o primeiro livro de casos. O surgimento de um livro de casos tornou possível a expansão do ensino de estratégia para outras universidades (BOWER, 2008).

A respeito do método de caso, Bower (2008) elucida que o mesmo é importante no ensino da gestão estratégica e que possui, como principal objetivo, o desenvolvimento da capacidade de análise estratégica, de pensamento estratégico, de comunicação, de habilidades interpessoais e de integração. Já para Argyris (1980), o método de casos proporciona uma 


\section{DESENVOLVIMENTO DO ENSINO DE ESTRATÉGIA EM CURSOS DE GRADUAÇÃO EM \\ ADMINISTRAÇÃO DE INSTITUIÇÕES DE ENSINO SUPERIOR PELA PERSPECTIVA DE PROFESSORES E ALUNOS \\ DOI: http://dx.doi.org/10.5007/1983-4535.2016v9n2p70}

aprendizagem que não questiona os valores dos executivos e as políticas organizacionais, além de que inibe o aprendizado que permite ao futuro executivo se questionar sobre esses valores. Outra limitação paira na questão de que os alunos necessitam ser preparados para dirigir corporações nacionais e multinacionais, tratando, implicitamente, de casos em grandes organizações (MACFARLANE; PERKINS, 1999).

Outra alternativa ao ensino de estratégia baseado em casos é apresentada por Grant (2008), que defende uma abordagem fundamentada na teoria, denominada de Análise Estratégica. Tal vertente originou-se em 1980, a partir da obra "Competitive Strategy", de Michael Porter (Porter, 1980), na qual modelos teóricos embasados em teorias economicistas foram aplicados para análise e desenvolvimento de estratégias organizacionais.

Grant (2008) aponta o conhecimento teórico como vertente principal na condução das organizações por seus gestores, os quais, após consolidarem uma base teórica, terão conhecimento e o discernimento necessários para tomar decisões estratégicas sólidas, não comprometendo o sucesso de sua organização. Não obstante, são levadas em conta situações estratégicas complexas, percebidas por meio de uma estrutura cognitiva derivada de uma teoria empiricamente validada, e não de uma sabedoria popular. Dessa forma, para Grant (2008), os alunos ganharão experiência por meio do contato com a teoria, o que permite a triangulação com problemas reais de negócios e de pesquisa, a fim de desenvolver a habilidade necessária para um futuro desempenho profissional (GRANT, 2008).

Ainda em relação ao ensino baseado em teorias, Goshal (2005) alerta que as pesquisas acadêmicas sobre as organizações exercem influências significativas e, por vezes, prejudiciais, sobre a gestão rotineira dessas organizações. Esse fato decorre da frequente adoção direta das teorias sem sua adaptação para a realidade gerencial e local. O autor afirma que, com a "propagação de teorias amorais, as escolas de negócios têm formado alunos com pouca responsabilidade moral" (GOSHAL, 2005, p. 77).

Outra ressalva à abordagem eminentemente teórica é feita por Mintzberg (1973), o qual afirma que procedimentos analíticos não podem ser aplicados em processos de trabalho que não são bem compreendidos. Dessa maneira, o modelo de planejamento racional não é aplicável diante da pouca estabilidade e da realidade de rápida mudança nas organizações. Os gerentes lidam com informações não documentadas que são difíceis de transmitir e usam métodos indutivos que são difíceis de entender (MINTZBERG, 1973). Portanto, o ensino de 


\section{DESENVOLVIMENTO DO ENSINO DE ESTRATÉGIA EM CURSOS DE GRADUAÇÃO EM \\ ADMINISTRAÇÃO DE INSTITUIÇÕES DE ENSINO SUPERIOR PELA PERSPECTIVA DE PROFESSORES E ALUNOS \\ DOI: http://dx.doi.org/10.5007/1983-4535.2016v9n2p70}

estratégia organizado em uma disciplina não consegue, por si só, desenvolver as habilidades e as atitudes necessárias aos gerentes (MINTZBERG; GOSLING, 2002).

Visando desenvolver essas habilidades necessárias aos gestores, Gosling e Mintzberg (2006) propõem um modelo de ensino de estratégia baseado em sete princípios: (1) docência em gestão deve ser restrita a gerentes praticantes, selecionados a partir de desempenho comprovado, pois o sucesso na atuação como administrador é a melhor qualificação para ensinar sobre o assunto; (2) os docentes devem continuar atuando como gestores para que possam abordar a aprendizagem em gestão por meio de suas práticas, pois experimentação concreta é uma maneira poderosa de incorporar novas ideias e técnicas; (3) o ensino de gestão possibilita o incremento da experiência empresarial e de vida de forma plena, pois a prática pode se refletir no processo da educação por meio de críticas dos assuntos discutidos em sala de aula; (4) o segredo para a aprendizagem é a reflexão minuciosa, que propicia um momento para o gestor analisar suas práticas sob outra perspectiva; (5) a reflexão em sala de aula deve produzir impacto na organização em que o docente atua; (6) a junção desses elementos ao ensino de gestão torna-se um processo interativo de aprendizagem, ocorrendo, com isso, (7) implicações profundas na estrutura, no corpo docente e na pedagogia do ensino de gestão, em que o docente tem o papel de facilitador.

Outra perspectiva para o ensino de estratégia é o embasado na visão da estratégia como uma prática social, proposto por Jarzabkowski e Whittington (2008). Esses autores propõem uma aproximação da pesquisa e do ensino de estratégia com a práxis nas organizações. Assim, a partir da pesquisa sobre a realização de estratégias nas organizações, é possível elaborar estratégias de ensino e, com isso, proporcionar aos alunos estudos de caso ricos, que demonstrem como a estratégia é praticada e pode ser analisada através das lentes sociológicas, como a etnometodologia e a teoria institucional. Esse tipo de ensino não tem como objetivo oferecer aos discentes apenas modelos para análise, mas também ajudá-los a desenvolver a sabedoria prática por meio de uma melhor compreensão da estratégia (JARZABKOWSKI; WHITTINGTON, 2008).

Além das diferentes abordagens de ensino apontadas, destacam-se também as técnicas de ensino enquanto ferramentas que os professores utilizam para interagir com o aluno e proporcionar aprendizagem. A discussão sobre assuntos atuais, uma das técnicas apresentadas por Jennings (1996), incentiva a participação dos alunos e proporciona inúmeras opiniões que poderão ser trabalhadas em sala. No entanto, pode gerar perda de foco, além de que o domínio 


\section{DESENVOLVIMENTO DO ENSINO DE ESTRATÉGIA EM CURSOS DE GRADUAÇÃO EM \\ ADMINISTRAÇÃO DE INSTITUIÇÕES DE ENSINO SUPERIOR PELA PERSPECTIVA DE PROFESSORES E ALUNOS \\ DOI: http://dx.doi.org/10.5007/1983-4535.2016v9n2p70}

da aula por um indivíduo de opinião forte pode dificultar sua aplicação. Da mesma forma, uma aula com o estudo de artigos científicos se constitui em uma possibilidade de auxiliar o docente a aprofundar questões específicas, podendo, porém, diminuir a motivação e a participação dos discentes (JENNINGS, 1996).

Entre as técnicas de ensino, encontram-se os jogos e as simulações, que, para Kayes (2002), permitem o aprendizado experimental e são ideais no ensino da administração, principalmente no ensino de administração estratégica. Os jogos de negócios, por sua vez, adicionam complexidade, experiência simulada e o sentimento de competição, bem como ajudam a projeção de cenários, gerando participação e interesse (JENNINGS, 1996). No que tange ao uso de simuladores, Haro e Turgut (2012) asseveram que permite ao aluno aprender com os próprios erros, o que oportuniza a relação entre conteúdo e prática gerencial. Tais técnicas exigem empenho do professor que, por meio de uma função ativa, estabelece as ligações de conteúdo, estimula a participação e controla o desempenho dos alunos (HARO; TURGUT, 2012). Contudo, Jennings (1996) alerta para os aspectos estáticos do jogo, os elevados custos da alocação de recursos e o consumo de tempo como fatores limitadores.

Jennings (1996) ainda cita os projetos de campo aplicados em organizações os quais permitem a interação entre teoria e prática, ampliam o entendimento do aluno e desenvolvem habilidades de pesquisa, além de facultarem ao acadêmico a escolha de organizações em áreas de seu interesse. Os principais impedimentos desse método são a restrição ao acesso das informações, a dificuldade de aplicação da teoria e o consumo de tempo para a realização das atividades.

Por fim, Jennings (1996) indica os projetos de consultoria como uma possibilidade pedagógica para o ensino de estratégia. A responsabilidade de relacionar-se com um cliente é um ponto forte do método, pois promove o desenvolvimento de habilidades comportamentais. As restrições geradas pelo pouco espaço para experimentações e pelas dificuldades de controle necessitam ser consideradas nessa abordagem.

Um estudo comparativo realizado por Jennings (2002) confrontou as técnicas de estudo de caso, simulação de um novo negócio e projetos de consultorias. Entre os resultados da pesquisa, o autor aponta que o uso de múltiplos métodos pode deixar o curso mais atrativo e, ainda, promover aprendizados complementares e integrados. Contudo, uma técnica particular, a simulação de negócios, gera rendimentos superiores no aprendizado, conforme a percepção dos acadêmicos. 


\section{DESENVOLVIMENTO DO ENSINO DE ESTRATÉGIA EM CURSOS DE GRADUAÇÃO EM \\ ADMINISTRAÇÃO DE INSTITUIÇÕES DE ENSINO SUPERIOR PELA PERSPECTIVA DE PROFESSORES E ALUNOS \\ DOI: http://dx.doi.org/10.5007/1983-4535.2016v9n2p70}

\subsection{O PAPEL DO DOCENTE E DO DISCENTE NO ENSINO DE ESTRATÉGIA}

O processo de objetivação de papéis sociais decorre da seguinte perspectiva: as ações humanas são consolidadas em forma de rotinas, quando realizadas de maneira recorrente e repetitiva. Assim, o conjunto de rotinas padroniza as condutas sociais em dado ambiente, permitindo a classificação em conjunto de comportamentos similares a determinados atores em determinado contexto (BERGER; LUCKMANN, 2012).

Na direção apontada, o papel, de acordo com Berger e Luckmann (2012), consiste em um conjunto de condutas socialmente compreendidas e internalizadas por um grupo de atores, os quais passam a reproduzi-lo no tempo, além de que se identificam de tal forma com esse grupo de condutas que estas passam, também, a representá-los.

Dessa maneira, tanto o indivíduo (singular) quanto os outros atuantes são entendidos como tipos de atores que executam as mesmas ações em uma coletividade, e não como indivíduos únicos (BERGER; LUCKMANN, 2012). Assim, os diversos indivíduos que lecionam estratégia caracterizam um tipo, pois, independentemente de cada um ser essa ou aquela pessoa singular, todos realizam as ações repetidas e recorrentes que envolvem a prática de ensinar estratégia.

A construção das tipologias de papéis, para Berger e Luckmann (2012), é necessária para a institucionalização da conduta, isto é, as instituições incorporam-se à experiência do indivíduo por meio de papéis, sendo que o ator (eu social), ao desempenhar papéis, participa de um mundo social, o qual, com a interiorização dos papéis desempenhados, se torna objetivamente real para o mesmo.

O professor pesquisador de estratégia, enquanto um papel tipificado, partilha e interage com os outros professores e/ou pesquisadores de estratégia, formando um mundo social, que passa a ser real a todos esses indivíduos (professores e/ou pesquisadores), os quais, por seu turno, tenderão a desenvolver conduta similar ao ensinar e/ou pesquisar sobre estratégia.

Nesse sentido, o professor que leciona estratégia executa a ação de ensinar, respeitando, no entanto, condutas objetivadas ao seu mundo social, pois ele representa não apenas o eu indivíduo, mas o papel social de professor de estratégia. Da mesma forma, aluno, envolvido em sua realidade, executa a ação de aprender e adquirir conhecimento, assumindo o papel de aprendiz na área. 


\section{DESENVOLVIMENTO DO ENSINO DE ESTRATÉGIA EM CURSOS DE GRADUAÇÃO EM \\ ADMINISTRAÇÃO DE INSTITUIÇÕES DE ENSINO SUPERIOR PELA PERSPECTIVA DE PROFESSORES E ALUNOS \\ DOI: http://dx.doi.org/10.5007/1983-4535.2016v9n2p70}

Cabe salientar que exercer um papel não se limita a compreender o sentido cognoscitivo estreito daquela atividade em relação ao seu desempenho exterior, mas também consiste na internalização de normas, valores e até emoções, que são próprios, diretamente e indiretamente, de determinado papel (BERGER; LUCKMANN, 2012). Portanto, o papel do professor é muito mais do que o de ensinar, e o do aluno vai além do ato de aprender.

Dooley e Skinner (1977) afirmam que a consolidação do papel do professor de estratégia pode ser entendida em três grandes dimensões: (a) os objetivos educacionais do professor, como, por exemplo, adquirir conhecimento, desenvolver conceitos, adquirir habilidades técnicas e comportamentais, obter capacidade de análise e síntese; (b) a fillosofia pedagógica e as convicções do professor, dimensão segundo a qual o aprendizado é uma responsabilidade do professor, até nas situações em que o aluno promove seu próprio aprendizado, e o professor é apenas um meio para alcançá-lo; (c) o entendimento do caráter do papel do professor e do aluno em sala de aula, isto é, os estilos de atuação do professor e as formas de interação com o aluno (DOOLEY; SKINNER, 1977).

Ainda sobre o papel do docente e do discente, Dooley e Skinner (1977) defendem que o aprendizado é um processo de autoeducação que compõe um extremo das possibilidades de delimitações pedagógicas. Nessa primeira extremidade, o professor é apenas um auxiliar, o qual sana as dúvidas e não se responsabiliza pelo aprendizado alheio, enquanto o aluno aprende "o que quer" no momento. Já, na extremidade oposta, o professor é o elemento decisivo no processo de aprendizado, sendo que seu conhecimento e sabedoria o colocam como componente central, atribuindo-lhe a responsabilidade no processo de ensinoaprendizagem (DOOLEY; SKINNER, 1977).

\section{PROCEDIMENTOS METODOLÓGICOS}

Os procedimentos adotados nesta pesquisa qualitativa fundamentam-se em um estudo de caso coletivo, o qual, de acordo com Stake (2005), permite evidenciar, com melhor clareza e entendimento, os fenômenos estudados devido às diferenças de discernimento e juízo de cada indivíduo e/ou grupo. Os sujeitos da pesquisa foram estudantes da disciplina de estratégia, do curso de Graduação em Administração, bem como seus professores de estratégia, aos quais se atribuiu as nomenclaturas Professor 1, Professor 2, Professor 3, Aluno 1, Aluno 2 e assim sucessivamente. 


\section{DESENVOLVIMENTO DO ENSINO DE ESTRATÉGIA EM CURSOS DE GRADUAÇÃO EM \\ ADMINISTRAÇÃO DE INSTITUIÇÕES DE ENSINO SUPERIOR PELA PERSPECTIVA DE PROFESSORES E ALUNOS \\ DOI: http://dx.doi.org/10.5007/1983-4535.2016v9n2p70}

Fez-se a coleta de dados entre os meses de maio e julho de 2013, em duas instituições de ensino superior, aqui denominadas de "A" e "B", sendo uma privada e uma pública, ambas situadas no Vale do Itajaí, SC, configuradas em uma perspectiva temporal de corte transversal. Estruturaram-se grupos de foco com discentes das disciplinas, sendo que se contou com a participação de 7 alunos da instituição pública e 8 da instituição privada, do oitavo e sétimo semestres, respectivamente. Com os docentes, realizaram-se três entrevistas em profundidade por meio de roteiro de entrevistas semiestruturado, sendo 2 da instituição privada e 1 da pública. Gravaram-se as entrevistas, das quais, posteriormente, se fez a transcrição literal. As mesmas totalizaram 3 horas e 25 minutos de gravação, com uma duração média de, aproximadamente, 40 minutos para os docentes e 38 minutos para os discentes, o que resultou em 125 páginas de transcrição. Também se realizou uma pesquisa documental por meio dos planos de ensino, o que, por sua vez, viabilizou a triangulação dos dados. Os dados terem sido obtidos de diferentes fontes possibilita mensurar com maior precisão e organização as informações.

Para a análise dos dados coletados, empregou-se, com base em Bardin (2010), a análise de conteúdo temática. Como ferramenta de auxílio à análise de conteúdo, utilizou-se o software Atlas.ti. versão 6, no qual os dados foram organizados e codificados, optou-se contudo não gerar as teias.

Como categorias de análise, empregaram-se: a) Papéis Assumidos pelos Professores de Estratégia, por meio da qual se buscou identificar as condutas e os padrões de ação comuns aos professores, ou um conjunto desses, com base na descrição das atividades, dos comportamentos e das rotinas dos professores, além de normas, valores e emoções; b) Corpo do Conhecimento em Estratégia, categoria composta pelas teorias de base, teorias de estratégia, abordagens e conceitos, ferramentas de análise e obras científicas utilizadas nas disciplinas; e c) Escolhas Pedagógicas no Ensino de Estratégia, por meio da qual se estabeleceu uma relação entre as escolhas pedagógicas e os diferentes métodos (método de caso, estudo analítico, mentalidade estratégia e ensino por meio da lente da prática social) e técnicas empregadas no ensino de estratégia (aulas expositivo-dialogadas, palestrantes convidados, vídeos, trabalhos sobre atualidades ou artigos científicos, seminários, jogos de negócios, simuladores, projetos aplicados a organizações e projetos de consultoria). 


\section{APRESENTAÇÃO E ANÁLISE DOS DADOS}

No que tange ao corpo de conhecimento de estratégia, de acordo com o grupo de foco desenvolvido com alunos da IES “A”, percebe-se que o ensino de estratégia na graduação possui influência de abordagens clássicas com foco na escola de planejamento estratégico. $\mathrm{O}$ conteúdo de formulação estratégica e diagnóstico estratégico é o mais trabalhado na disciplina.

Além do conteúdo da escola de planejamento, a disciplina também abrange ferramentas de outras escolas da estratégia, como a análise SWOT - Forças (Strengths), Fraquezas (Weaknesses), Oportunidades (Opportunities) e Ameaças (Threats) desenvolvida por Andrews (1971) da escola de Design, conforme relata o Aluno 1:

\footnotetext{
no trabalho da disciplina, a gente está indo agora para a etapa dos pontos fortes, pontos fracos [...]. Como tem que ser aplicado em uma empresa, a gente avalia a situação do planejamento da empresa e monta, no caso, uma opção do planejamento com base em nosso diagnóstico. Este é o resultado principal da matéria.
}

Outra ferramenta apontada pelos alunos da mesma IES relaciona-se ao modelo de análise das cinco forças de Porter (1980) da escola do posicionamento estratégico. O Aluno 3 afirma: "na verdade, através dessa análise que a gente vai conseguir fazer o planejamento estratégico e fazer o posicionamento estratégico, ou seja, como é que a empresa vai se posicionar perante o mercado". Percebe-se, também, que a disciplina está focada em diagnóstico estratégico, o que contempla a elaboração de missão, visão e valores e o negócio da empresa, ou seja, formulação da estratégia:

se um dia eu quiser abrir uma empresa, tenho que saber qual a visão da empresa, a missão, qual meu negócio, principalmente o negócio da empresa onde quero atuar, qual são os meus clientes... por isso a disciplina é muito importante. [...] tu conhecer realmente a visão da tua empresa, a missão, com essa base você vai desenvolvendo a empresa (Aluno 3).

No que tange à utilização de obras, são empregadas, nesta disciplina, como bibliografia básica, as obras "Planejamento estratégico", de Andrade (2012), e "Administração estratégica", de Hitt, Hoskisson e Ireland (2002). Esses livros são utilizados como manuais, e a disciplina se desenvolve a partir dos conteúdos apresentados por esses autores. Destaca-se que tais livros focam, principalmente, a formulação da estratégia, embasados na escola do planejamento. 


\section{DESENVOLVIMENTO DO ENSINO DE ESTRATÉGIA EM CURSOS DE GRADUAÇÃO EM \\ ADMINISTRAÇÃO DE INSTITUIÇÕES DE ENSINO SUPERIOR PELA PERSPECTIVA DE PROFESSORES E ALUNOS \\ DOI: http://dx.doi.org/10.5007/1983-4535.2016v9n2p70}

$\mathrm{O}$ enfoque particular em planejamento estratégico permite um aprofundamento do discente no que se refere à formulação de estratégias. Contudo, tal fato também constitui uma limitação ao aprendizado, uma vez que os alunos entendem o planejamento estratégico como a totalidade do conteúdo em estratégia.

A IES " $\mathrm{B}$ " igualmente conduz a disciplina de estratégia voltada para a perspectiva Clássica, todavia, com foco, todavia, em planejamento e posicionamento estratégico, sobremaneira, na abordagem da vantagem competitiva (PORTER, 1980). No entanto, identificaram-se, também, conteúdos referentes à abordagem processual, como, por exemplo, as estratégias emergentes, de Mintzberg (1978); Visão Baseada em Recursos (VBR), de Barney (1991); Teoria da Agência (stakeholders), de Freeman e Reed (1984); Teoria do Desenvolvimento Econômico, de Schumpeter (1911) e a abordagem de Estratégia Como Prática, de Whittington (1996), conforme apontam as falas a seguir:

$\mathrm{O}$ [nome do professor] trouxe artigos atuais, [...] que falavam sobre esses assuntos de estratégia [...]. São assuntos antigos, mas que estão [...] moldados na realidade, então fica um pouco mais palpável, assim, para gente ligar com a realidade que acontece nas empresas (Aluno 10). São 8 teorias [...], Legitimidade, Redes, Isomorfismo, stakeholders, Monitoramento do Ambiente, Visão baseada em Recursos e Forças Competitivas e Desenvolvimento econômico (Aluno 9).

Quanto às obras básicas de teorias, o Professor 2, titular da disciplina na IES "B", esclarece que não as utiliza, por se tratar de uma disciplina ministrada para a graduação, conforme trecho destacado:

Eu teria preferência de usar claro, as obras preliminares [...], mas são alunos de graduação. Então a gente tem um perfil específico aqui do nosso aluno. Então, por exemplo, quando eu trabalho com Schumpeter, não necessariamente eles manipulam a obra original do Schumpeter, [...], até porque seria difícil. Mas o que eu uso? Um artigo científico que fala sobre o Schumpeter para o aluno entender aquele contexto e daí eu começo a retomar conteúdos que tem, por exemplo, dentro da obra original.

Assim como na instituição "A", percebe-se que o uso de teorias e de ferramentas do planejamento estratégico se encontra atrelado, conforme destacado pelo professor 2 :

Vou utilizar de base a Teoria da Visão Baseada em Recursos, onde eu vou olhar para
os meus recursos internos para saber como que eu posso atingir a vantagem
competitiva para que do que eu tenho ou que eu preciso buscar. Então, nesse
sentido, vamos construindo essa parte ferramental, digamos, da própria dinâmica da
estratégia (Professor 2).

Para a dinâmica de ensino exposta pelo Professor 2, além de apresentar algumas obras básicas das abordagens clássica e processual, o Professor 3, também da IES “B”, utiliza 


\title{
DESENVOLVIMENTO DO ENSINO DE ESTRATÉGIA EM CURSOS DE GRADUAÇÃO EM \\ ADMINISTRAÇÃO DE INSTITUIÇÕES DE ENSINO SUPERIOR PELA PERSPECTIVA DE PROFESSORES E ALUNOS \\ DOI: http://dx.doi.org/10.5007/1983-4535.2016v9n2p70
}

periódicos da Associação Nacional de Pós-Graduação e Pesquisa em Administração (ANPAD), a fim de expor os conteúdos por meio de um material compatível com a realidade do corpo discente, e não apenas em livros didáticos, o que se constitui (utilização de livros) uma prática frequente nesse nível de ensino. Tal dinâmica do estudo de artigos da ANPAD é detalhada pelo Professor 3:

\begin{abstract}
O que fortemente temos feito em nossa instituição, em decorrência dos alunos já estarem na fase do sétimo semestre e do projeto de TCC, estes já estão muito acostumados a não trabalhar só com livro didático. Desta forma, disponibilizamos artigos para eles, temos assinatura dos periódicos da ANPAD. Aí fazemos com que eles busquem no banco de artigos da ANPAD aqueles artigos para trabalhar teoria, tanto no TCC, quanto no plano de negócios. No plano de negócios, eles têm muito pouca teoria, mas eles têm como falar para mim o que é cada uma das coisas que eles estão desenvolvendo, de forma teórica, [...] não como no TCC, que é mais teoria [...], e em sala também já temos trabalhado com artigos.
\end{abstract}

Portanto, quanto ao corpo de conhecimento de estratégia, as disciplinas da graduação estudadas concentram seus esforços na abordagem clássica da estratégia, fundamentalmente no planejamento estratégico. Contudo, na disciplina ministrada na IES "B", encontraram-se tópicos relacionados, também, à abordagem processual.

Além disso, em ambas as instituições, o conteúdo de estratégia é ministrado com caráter de formulação, não abordando a implementação da estratégia. Esses aspectos convertem o aprendizado de estratégia a um conteúdo limitado, dificultando, assim, o entendimento amplo da relação formulação-implementação.

No que concerne às escolhas pedagógicas para o ensino de estratégia, ambas as IES caracterizam-se como Capstone Course, ou seja, desenvolvem a disciplina de estratégia ao final do curso, coroando e interligando com as demais áreas de estudo desenvolvidas durante o curso, como, por exemplo, recursos humanos, produção, finanças e marketing. Essa formação da disciplina ao final do curso é originaria da disciplina Políticas de Negócios, em Harvard (BOWER, 2008).

No entanto, existem opiniões divergentes entre os alunos da IES “A”, pois alguns alunos acreditam que é importante que a grade curricular do curso contemple disciplinas como recursos humanos, contabilidade e marketing no mesmo semestre da disciplina de estratégia, conforme expressa o Aluno 3: 
Talvez aproximar as matérias que se relacionam com estratégia e planejamento estratégico [...], por exemplo, teve contabilidade no começo do curso, agora no final do curso a gente [...] está tendo planejamento. O RH [recursos humanos] foi no $5^{\circ}$ semestre e no $8^{\circ}$ a gente está tendo planejamento, então, talvez aproximar estas matérias, seja importante para ampliar o aprendizado do curso.

Já o Professor 1 entende que a disciplina da estratégia necessita ser alocada na grade curricular após a primeira metade do curso de administração: "Não precisa ser no último semestre, mas eu prefiro que fique mais pelo quinto, sexto [semestre], a hora que o pessoal já está $[\ldots]$ se profissionalizando, têm um vocabulário mais desenvolvido e um entendimento mais adequado para a disciplina".

De maneira complementar, outro aluno salienta a importância de as disciplinas específicas serem aplicadas antes da disciplina de estratégia:

Para mim é correto conhecer cada área da empresa para depois [...] saber planejar, fazer o planejamento e delinear as estratégias. Se a gente talvez tivesse antes a disciplina, [...] não ia entender a importância da matéria. Desta maneira, [a disciplina ao final do curso] a gente tem uma mente mais aberta de como funciona cada setor da empresa para saber como [...] planejar e elaborar suas estratégias (Aluno 4).

Quanto às técnicas utilizadas pela IES “A”, nota-se que as aulas são desenvolvidas de maneira expositivo-dialogada, centradas na figura do docente como transmissor do conhecimento, além de serem enriquecidas por exemplos de consultorias realizadas na área pelo docente. Contudo, há, também, em momentos específicos, espaço para a discussão interativa entre o professor e o aluno (Jennings, 1996), conforme a fala do Professor 1:

Eu utilizo aula expositiva com o ensino de teoria sobre o assunto, discussão de tema e eu procuro usar muito exemplo, ai é que a consultoria ajuda, que a gente tem muito exemplo para trazer para sala de aula. Eu provoco eles para trazer exemplo das empresas onde eles trabalham e tem toda uma discussão em sala.

$\mathrm{Na}$ disciplina de estratégia da IES “A”, os alunos também elaboram um trabalho semestral de consultoria, conforme esclarecimento do Professor 1:

A disciplina é dividida em duas partes, digamos assim, $60 \%$ do tempo é discussão do texto, leitura, trabalho, mais de abordagem teórica firme. E o restante é composto por um trabalho que eles têm que desenvolver no decorrer do semestre. Este trabalho visa elaborar uma proposta de planejamento estratégico para uma empresa da região, e o roteiro que eles usam é o mesmo que eu uso na consultoria, a única diferença, por exemplo, é o volume de informações levantadas e a abrangência do trabalho.

O uso de múltiplos métodos - no caso da disciplina da IES “A”, aula expositiva e trabalho de consultoria -, caracteriza-se pela possibilidade de promover resultados 


\section{DESENVOLVIMENTO DO ENSINO DE ESTRATÉGIA EM CURSOS DE GRADUAÇÃO EM \\ ADMINISTRAÇÃO DE INSTITUIÇÕES DE ENSINO SUPERIOR PELA PERSPECTIVA DE PROFESSORES E ALUNOS \\ DOI: http://dx.doi.org/10.5007/1983-4535.2016v9n2p70}

complementares no aprendizado, consistindo em um atrativo e fazendo com que o aprendizado do aluno seja conectado com situações da vida profissional (JENNINGS, 2002).

Contudo, Jennings (2002) aponta dificuldades no trabalho semestral de consultoria realizado pelos alunos, principalmente pelo curto espaço de tempo disponível para o desenvolvimento de um trabalho robusto, resultando, via de regra, em uma simplificação da realidade vivenciada, gasto excessivo de tempo e esforço dos envolvidos. Esse método também vai ao encontro da proposição de Gosling e Mintzberg (2006), pois o professor busca facilidade em repassar seus conhecimentos aos discentes e trabalha a estratégia como modelo de formulação da estratégica. Contudo, na proposta dos autores, há a necessidade de ampliar a capacidade de reflexão dos alunos (Gosling e Mintzberg, 2006), característica não observada no caso em estudo.

Já, quanto às técnicas de ensino utilizadas na IES “B”, os alunos apontam a leitura de artigos, a apresentação de seminários e as discussões em grupo como os principais pontos relacionados à aprendizagem:

A gente está saindo agora, desse semestre sabendo [...] como "linkar" [...] as teorias de estratégia, porque [...] a metodologia de distribuir textos teóricos para gente, com várias abordagens de estratégia e por meio de apresentações, a gente explicava para os outros colegas. O que ficava de dúvidas depois, a gente fazia um debate e [...] conversava em grupo e tirava as dúvidas com o professor, [...] dialogando, assim gravamos bem o conteúdo, porque, $[\ldots]$ com esse debate parece que conseguimos gravar mais [...] (Aluno 12).

Para Jennings (1996), as técnicas de leitura de artigos científicos, de apresentação de seminários e de discussões em classe aprofundam o conhecimento, levando a questões mais específicas de cada tema, ampliam o envolvimento do aluno e o preparam para o mercado e também para a pesquisa.

Os alunos indicam que essa experiência de um professor repassar o conteúdo de forma descentralizada é advinda de sua experiência como aluno no doutorado, o qual adaptou para suas aulas na graduação:

Em outras disciplinas que a gente teve com [nome do professor], a gente já percebia isso (aluno 12). Eu acho que é reflexo até do doutorado dele. Então ele já teve uma boa bagagem de como usar a metodologia correta, como fazer, então eu acho que ajudou a trazer [...] para sala de aula esta abordagem diferenciada. Muitos professores não se interessam nisso assim, pensam que é só ali falar e pronto! Tendo conhecimento, não quanto ao conteúdo da aula, mas também a maneira de conduzila (Aluno 13). 


\section{DESENVOLVIMENTO DO ENSINO DE ESTRATÉGIA EM CURSOS DE GRADUAÇÃO EM \\ ADMINISTRAÇÃO DE INSTITUIÇÕES DE ENSINO SUPERIOR PELA PERSPECTIVA DE PROFESSORES E ALUNOS \\ DOI: http://dx.doi.org/10.5007/1983-4535.2016v9n2p70}

Entre as técnicas de ensino mais praticadas na disciplina de estratégia na IES "B, destaca-se, portanto, a técnica de seminário por provocar nos alunos a necessidade da leitura, preparação e reflexão antecipada de textos que são apresentados e estão interligados com os conteúdos das abordagens estudadas nas aulas anteriores, como elucida o Aluno 8:

E depois [...] na próxima aula, a gente chegava já com ideias formuladas na cabeça para fazer o contexto. A gente tinha que fazer um contexto sozinho sobre aquele assunto e ligar com o outro anterior. Ele (o professor) estava sempre junto, de vez em quando a gente pedia auxílio e ele orientava. Mas a gente que tinha que criar, então já começa mudar a forma de pensar.

Percebe-se, com a fala do Aluno 8, o incentivo à reflexão dos alunos conforme a metodologia sugerida por Gosling e Mintzberg (2006), na qual a junção da reflexão com o ensino em sala torna a disciplina um processo interativo de aprendizagem.

Quanto aos métodos utilizados em classe, os alunos ressaltam a discussão em grupo, como o debate sobre as teorias aprendidas por meio da leitura de artigos e livros didáticos, bem como com a experiência do docente que estimula o raciocínio e comprometimento do discente. Grant (2008) defende esse tipo de abordagem, considerando-o como o desenvolvimento da capacidade analítica por meio do ensino teórico, a qual, por sua vez, se caracteriza como aspecto imprescindível na estruturação intelectual do aluno. Nesse sentido, o autor também salienta o ganho de experiência em estratégia mediante contato com a teoria e diante da triangulação com problemas reais das organizações, a fim de formar um profissional com habilidades estratégicas para tomada de decisão e liderança organizacional.

Entende-se que esse tipo de método de ensino busca alcançar o aprendizado do aluno na íntegra, existindo, no entanto, pontos ou riscos a serem considerados. Como exemplo, citam-se a exigência de leitura e o comprometimento do aluno para tal atividade, bem como sua participação ativa. Atualmente, tais elementos são difíceis de trabalhar na realidade dos cursos de graduação, exigindo do docente um esforço de motivação e cobrança dos acadêmicos.

Para o ensino de estratégia desenvolvido, as IES “A” e "B" dispõem de professores com título de doutores, estando um em cada instituição, e de mais um doutorando na IES privada. Percebe-se a busca constante dos professores por aprimoramento e qualificação, como expõe o Professor 1: "me formei em 81 e depois eu fui fazer o mestrado pra ter uma titulação de peso [...] e acabei o mestrado em 87. [...] Então, tanto que depois eu fiz doutorado 


\section{DESENVOLVIMENTO DO ENSINO DE ESTRATÉGIA EM CURSOS DE GRADUAÇÃO EM \\ ADMINISTRAÇÃO DE INSTITUIÇÕES DE ENSINO SUPERIOR PELA PERSPECTIVA DE PROFESSORES E ALUNOS \\ DOI: http://dx.doi.org/10.5007/1983-4535.2016v9n2p70}

[...] todo na área de Estratégia [...] na Espanha". Quanto à sua formação, o Professor 2 assim se expressa:

A minha primeira graduação é Comunicação Social com habilitação em Publicidade e Propaganda, [...] um MBA [...] em Gestão Estratégica Organizacional, [...] mestrado em Administração de Negócios [...]e o doutorado em Administração [...] eu também [...] concluí a graduação de Administração.

Quanto ao Professor 3, tem-se a seguinte fala: “em 99 [...] saí da graduação direto para o mestrado, que concluí [...] na metade de 2003. [...] demorei um pouco e agora em 2011eu entrei no doutorado de Ciências Contábeis e Administração”.

Já diante da conduta dos docentes das IES "A" e "B", percebe-se a diferença no aspecto de ensinar. Sobre a IES "A", nota-se que o professor caracteriza-se como centralizador, condutor ou demonstrador, ou seja, conduz o aluno ao resultado que ele espera. Esse tipo de personagem, para Dooley e Skinner (1977), conduz o raciocínio do discente por meio da realização de problemas e análises, prioriza a solução dos casos, demonstra e finaliza com a resposta correta.

Já a IES “B” possui professores de estratégia com conduta de facilitador, ou seja, conduzem o início e o final dos estudos, incentivando e promovendo os debates e as discussões, não repreendendo as ideias dos alunos e auxiliando no andamento até a finalização dos estudos. Para Dooley e Skinner (1977), nesse sentido, o papel do professor é apenas de auxiliar, sanar as dúvidas, não se responsabilizando pelo aprendizado alheio, enquanto o aluno aprende "o que quer" no momento que desejar.

Para diferenciar tais condutas, buscaram-se identificar as rotinas dos docentes de cada IES pesquisada. Sobre a conduta do professor da IES “A”, percebe-se a cobrança maciça de leitura do material disponibilizado, a realização de chamada dos alunos, a realização de provas com 5 questões abertas (discursivas) e a orientação dos trabalhos a serem realizados em classe, conforme explica o Aluno 1: "primeiro ele faz a parte do livro e depois [...] ele vai acompanhando no trabalho".

Nas rotinas dos professores da IES "B", percebem-se semelhanças nas condutas quanto à cobrança nas leituras e à pontualidade nos trabalhos a serem entregues. No entanto, identificaram-se variáveis que modificam a conduta do professor em classe, principalmente no que tange à disponibilidade de material com uma semana de antecedência, para a 


\section{DESENVOLVIMENTO DO ENSINO DE ESTRATÉGIA EM CURSOS DE GRADUAÇÃO EM \\ ADMINISTRAÇÃO DE INSTITUIÇÕES DE ENSINO SUPERIOR PELA PERSPECTIVA DE PROFESSORES E ALUNOS \\ DOI: http://dx.doi.org/10.5007/1983-4535.2016v9n2p70}

preparação do seminário pelos alunos e a realização das provas que se focalizam em 10 questões, sendo 8 abertas (discursivas) e 2 fechadas (objetivas).

Evidenciou-se nas duas IES a existência de outros atores, os quais podem gerar mudanças no papel do professor e/ou do aluno, por meio de modificações no padrão de conduta objetivado na sociedade. Um dos atores mencionado com frequência nas entrevistas é o Ministério da Educação (MEC), que aponta diretrizes a serem seguidas pelo Núcleo Docente Estruturante (NDE) do curso, como cita o Professor 2: "isso tem dentro da graduação [...] o NDE que é o núcleo do docente estruturante do curso, ele que pensa estrategicamente o curso, pensando nas diretrizes que o MEC aponta”. O Professor 3 também identifica o MEC como um ator: "Eu acho que hoje, a influência maior é [...] o MEC que não diz como fazer, [...] mas como a gente vai ser cobrado por ele [...]". Essas influências do MEC podem ocorrer por meio de regulamentações, de criação de práticas organizacionais e de reforços de padrões de conduta.

Outro fator elaborado pelo MEC, que influencia as condutas dos docentes, é o Exame Nacional de Desempenho de Estudantes (ENADE), pois é por meio desse exame que o rendimento dos alunos é mensurado, nos cursos de graduação. A justificativa, por exemplo, de as obras de Porter serem abordadas frequentemente nas IES "A" e "B" encontra-se relacionada à presença dessas obras nos exames de 2006, 2009 e 2011 do ENADE. Percebe-se que o contato com a teoria das abordagens clássica e processual, direcionados a Porter, é de fundamental importância para os alunos da disciplina de estratégia, como relatado pelo Professor 3:

Então assim [...] tem uma influência hoje, a prova de 2009 teve mais questões que a de 2011 de Estratégia, na análise que a gente fez, só que ela está vindo assim [...] Antes vinha: As estratégias de Porter, e as forças competitivas do Porter estavam praticamente em todas as provas, a de 2006, 2009, 2011 caiu questão relacionada a isso, então elas ainda estão puxando mais para uma abordagem Clássica e Processual.

Salienta-se, ainda, a relação da IES "B" com a ANPAD, no que tange ao seu referencial para o desenvolvimento de pesquisas na área, conforme destacado pelo Professor 3: "a gente já tem disponibilizado bastante artigos para eles [alunos]. A gente tem assinatura aqui dos periódicos da ANPAD [...] e já tem muito certo que eles vão buscar, [...]estes artigos para trabalhar teoria, tanto no TCC, quanto no plano de negócio". 


\section{DESENVOLVIMENTO DO ENSINO DE ESTRATÉGIA EM CURSOS DE GRADUAÇÃO EM \\ ADMINISTRAÇÃO DE INSTITUIÇÕES DE ENSINO SUPERIOR PELA PERSPECTIVA DE PROFESSORES E ALUNOS \\ DOI: http://dx.doi.org/10.5007/1983-4535.2016v9n2p70}

Em suma, exercer o papel de professor de estratégia não é apenas adquirir e transmitir conhecimentos relacionados à estratégia, evidenciando-se uma série de elementos (rotinas, condutas, normas, valores e emoções) próprios desse papel.

\section{CONSIDERAÇÕES FINAIS}

Pretendeu-se analisar, com esta pesquisa, o desenvolvimento do ensino de estratégia em cursos de graduação em Administração de IES do Vale do Itajaí pela perspectiva de professores e de alunos. Quanto ao corpo de conhecimento em estratégia, identificou-se a presença das abordagens clássicas referenciadas por Chandler e Porter. No que concerne a essa abordagem, notou-se o ensino-aprendizagem voltado principalmente para planejamento estratégico e posicionamento competitivo. No entanto, a pesquisa também revelou a presença de disciplinas que abordam a perspectiva processual, com ênfase nas estratégias emergentes de MINTZBERG (1978).

Quanto ao material didático utilizado nas disciplinas, constatou-se que ambas as IES trabalham com livros de autores clássicos nacionais e internacionais, bem como de maneira inovadora com artigos do periódico ANPAD, trazendo aos alunos trabalhos atualizados com diferentes perspectivas.

Um fato percebido neste trabalho foi que as IES direcionam a atenção ao ENADE. Este exame, de acordo com as entrevistas realizadas, enfatiza, em suas questões, a abordagem clássica, como também a presença de obras de Porter. Para tal, as IES concentram os ensinamentos da disciplina de estratégia nesta perspectiva a fim de buscarem o melhor resultado no exame.

Sobre os métodos pedagógicos, não houve uma convergência das duas IES pesquisadas quanto ao modelo de ensino, visto que a IES "A" trabalhava com um modelo mais atrelado ao diagnóstico estratégico, sendo o método utilizado a interação entre a teoria de planejamento estratégico e a aplicação em uma empresa, enquanto a IES “B” pesquisada, o modelo utilizado aproxima-se do analítico, por privilegiar as discussões teóricas (GRANT, 2008). Esse método pretende criar a mentalidade estratégica abordada por Gosling e Mintzberg (2006), com o intuito de ampliar o poder de tomada de decisão do aluno para sua futura atuação no mercado de trabalho.

Quanto às técnicas de ensino, a IES “A” utiliza a aula expositivo-dialogada como seu principal meio de ensino, como também um trabalho de consultoria que permeia o semestre 


\section{DESENVOLVIMENTO DO ENSINO DE ESTRATÉGIA EM CURSOS DE GRADUAÇÃO EM \\ ADMINISTRAÇÃO DE INSTITUIÇÕES DE ENSINO SUPERIOR PELA PERSPECTIVA DE PROFESSORES E ALUNOS \\ DOI: http://dx.doi.org/10.5007/1983-4535.2016v9n2p70}

inteiro. Quanto a esse tipo de trabalho, Jennings (1996) aponta, como fraquezas, que resulta, via de regra, em uma simplificação da realidade vivenciada, além de exigir esforços relevantes dos envolvidos e gasto excessivo de tempo. Já a IES “B” transforma suas aulas em seminários e discussão em grupos, com o intuito de desenvolver a reflexão, a argumentação e a iniciativa do discente. Tal abordagem vai ao encontro da proposta de Gosling e Mintzberg (2006), segundo a qual a junção da reflexão com o ensino em sala torna a disciplina um processo interativo de aprendizagem.

Quanto ao papel do professor, evidenciou-se que a disciplina da IES "A" é voltada para aulas expositivas, nas quais o docente centraliza o papel de difusor do conhecimento, conduzindo o aluno ao resultado por ele esperado. O docente, com essas características, para Dooley e Skinner (1977), manipula ou conduz o raciocínio do aluno, por meio da realização de problemas e análises, priorizando a solução dos casos e, em consequência, demonstrando os exercícios envolvidos na disciplina e os finalizando com a resposta correta. Na IES "B", por sua vez, o professor atua como um intermediário do aprendizado, no sentido de direcionar as discussões, ampliar a interação da turma e potencializar o aprendizado, ou seja, com uma conduta diferente. Esse tipo de professor é caracterizado como facilitador para resolução dos casos, deixando, porém, os alunos chegarem ao resultado individualmente ou em grupo. Nesse cenário, o docente conduz os estudos do início ao final, incentivando e promovendo os debates e as discussões, não repreendendo as ideias dos alunos e auxiliando no andamento até a finalização dos mesmos (DOOLEY; SKINNER, 1977).

Quanto à tipificação de condutas, percebeu-se um padrão de ação dos professores no que tange à cobrança de leitura e à pontualidade na entrega de atividades. Assim, o professor de estratégia, por meio da tipificação de condutas, partilha e interage com os outros professores de estratégia, formando um mundo social, que passa a ser real para todos esses indivíduos (professores), os quais tenderão a desenvolver conduta similar ao ensinar a estratégia (BERGER; LUCKMANN, 2012). Nesse contexto, salienta-se que os indivíduos (professores de estratégia) possuem ações específicas, sendo que essas ações são tipificadas como formas de ação, ou seja, padrões coletivamente objetivados de ensinar, de repassar ou de difundir o conhecimento de estratégia.

Como contribuição teórica, este estudo permitiu um resgate da Sociologia do Conhecimento de Berger e Luckmann (2012), combinando-o com a área de estratégia. Tal 


\section{DESENVOLVIMENTO DO ENSINO DE ESTRATÉGIA EM CURSOS DE GRADUAÇÃO EM \\ ADMINISTRAÇÃO DE INSTITUIÇÕES DE ENSINO SUPERIOR PELA PERSPECTIVA DE PROFESSORES E ALUNOS \\ DOI: http://dx.doi.org/10.5007/1983-4535.2016v9n2p70}

combinação de teorias oportuniza o tratamento, bem como a análise e a apresentação dos resultados com maior profundidade e precisão.

Como resultados empíricos esta pesquisa esclarece, com base na realidade das duas instituições, que não existe um "the best way" para ensinar a estratégia. A construção da disciplina dependerá, portanto, do alinhamento entre proposta pedagógica do curso, papel e experiência do docente, e métodos e técnicas de ensino, como também de parcelas de conhecimento em estratégias selecionadas para a construção e realização de uma disciplina.

Quanto à Sociologia do Conhecimento, Berger e Luckmann (2012) consideram que sua função não consiste em identificar e demonstrar as distorções causadas na sociedade, mas no estudo sistemático das condições sociais do conhecimento. Apesar da existência de diferenças dos resultados mensurados nesta pesquisa que focou as duas IES, ressalta-se que não há concorrência entre ambas. Salienta-se, ainda, que tal diferença corresponde a uma importante ampliação do conhecimento na área de estratégia.

A partir dos resultados obtidos, é possível questionar alguns dos aspectos objetivados, ou seja, considerados realidades inegáveis (Berger e Luckmann, 2012) a respeito dos papéis a serem assumidos pelos professores. No ensino da graduação, por exemplo, um entrevistado destaca que não é possível aprofundar conteúdos nem abordar concepções de estratégia que extrapolem as expectativas dos alunos. Nesse sentido, considera-se viável uma reflexão mais profunda sobre o que ensinar na graduação. Será que os professores não estão sendo econômicos em termos de profundidade no ensino de estratégia na graduação? Se o aluno não aprender na graduação, aprenderá somente na prática organizacional? Os profissionais que completam o mestrado estão tendo uma visão das diferentes possibilidades de ensino e de pesquisa em estratégia?

A fim de ampliar os resultados deste trabalho, indica-se, para futuros estudos a pesquisa em outras instituições de ensino, como também com diferentes professores e alunos que direcionam suas disciplinas e atividades nessa mesma área, com o objetivo de estudar as semelhanças e diferenças internas relacionadas ao ensino-aprendizagem das instituições.

Como limitação da pesquisa, afirma-se que os resultados apresentados são próprios das duas instituições em estudo e que, pelas características da pesquisa, não podem ser generalizados para outras instituições. Contudo, com um estudo ampliado poderia atingir uma categorização analítica do ensino de estratégia no Brasil. 


\section{REFERÊNCIAS}

ANDRADE, Arnaldo. R. de. Planejamento Estratégico: Formulação, Implementação e Controle. São Paulo: Atlas, 2012.

ANDREWS, Kenneth. R. The concept of corporate strategy. Homewood IL: Richard D. Irwin, 1971.

ANSOFF, Igor. Estratégia empresarial. São Paulo: McGraw Hill, 1977.

BARDIN, Laurence. Análise de conteúdo. Lisboa: Edições 70, 2010.

BERGER, Peter; LUCKMANN, Thomas. A construção social da realidade: tratado de sociologia do conhecimento. 34. Ed. Petrópolis: Editora Vozes, 2012.

BERTERO, Carlos O. et al. Estratégia empresarial: a produção científica brasileira entre 1991 e 2002. Revista de Administração de Empresas - RAE. São Paulo, v. 43, n. 4, p. 48-62, out/dez. 2003.

BOWER, Joseph L. The teaching of strategy: from general manager to analyst and back again? Journal of Management Inquiry, v. 17, n. 4 , p. 269-275, dec. 2008.

CHANDLER, Alfred D. Strategy and structure. Chapters in the history of the american industrial enterprise. Cambridge, MA: MIT Press, 1962.

CYERT, Richard; MARCH, James. A behavioral theory of the firm. London : Blackwell, 1963.

DOOLEY, Arch R. D.; SKINNER, Wickhan. Casing case method methods. The Academy of Management Review, v. 2, n. 2, p. 277-289, abr., 1977.

GOSHAL, Sumantra. Bad management theories are destroying good management practices. Academy of Management Learning \& Education, 4(1), 75-91, 2005.

GOSLING, Jonathan; MINTZBERG, Henry. Management education as if both matter. Management Learning, v. 37, n. 4, p. 419-428, 2006.

GRANT, Robert. M. Why strategy teaching should be theory based. Journal of Management Inquiry, v. 17, n. 4, p. 276-281, dez., 2008.

HANNAN, Michael T.; FREEMANN, Jonh. The population ecology of organizations. American Journal of Sociology, 82, 929-964. 1977.

HARO, Serge P.; TURGUT, Gokhan. Expanded strategy simulations: developing better managers. Journal of Management Development, 31(3), 209-220. 2012. 


\section{DESENVOLVIMENTO DO ENSINO DE ESTRATÉGIA EM CURSOS DE GRADUAÇÃO EM \\ ADMINISTRAÇÃO DE INSTITUIÇÕES DE ENSINO SUPERIOR PELA PERSPECTIVA DE PROFESSORES E ALUNOS \\ DOI: http://dx.doi.org/10.5007/1983-4535.2016v9n2p70}

JARZABKOWSKI, Paula; WHITTINGTON, Richard. A strategy-as-practice approach to strategy research and education. Journal of Management Inquiry, v. 17, n. 4, p. 282-286, dez., 2008.

JENNINGS, David. Strategic management and the case method. Journal of Management Development, v. 15, n. 9, p. 4-12, 1996.

JENNINGS, David. Strategic management: an evaluation of the use of three learning methods. Journal of Management Development, v. 21, n. 9, p. 655-665, 2002.

MACFARLANE, Bruce; PERKINS, Andrew. Reconceptualising corporate strategy in business and management education. Education + Training, 41(1), 20-26. 1999.

MINTZBERG, Henry. The nature of managerial work. New York: Harper Collins Publishers. 1973.

MINTZBERG, Henry. Patterns in strategy formation. Management Science, 24(9), 934948. 1978.

MINTZBERG, Henry et al. Safári de estratégia: um roteiro pela selva do planejamento estratégico. Porto Alegre: Bookman, 2000.

MINTZBERG, Henry; GOSLING, Jonathan. Managers beyond borders. Academy of Management Learning \& Education, 1(1), 64-76. 2002.

MINTZBERG, Henry et al. O processo da estratégia: conceitos, contextos e casos selecionados. 4. Ed. Porto Alegre: Bookman, 2006.

MINTZBERG, Henry. Os 5 Ps da estratégia. In: MINTZBERG, H.; LAMPEL, J.; QUINN, J. B.; GHOSHAL, S. O processo da Estratégia. 4. Ed. Porto Alegre: Bookmann, 2006.

NICOLINI, Alexandre. Qual será o futuro das fábricas de administradores? Revista de Administração de Empresas - RAE. São Paulo, v. 43, n. 2, p. 44-54, abr/jun. 2003.

PORTER, Michael E. Competitive strategy: techniques for analyzing industries and competitors. External links, 1980.

PORTER, Michael E. Vantagem competitiva: criando e sustentando um desempenho superior. 22. Ed. Rio de Janeiro: Campus, 2002.

STAKE, Robert E. Qualitative case studies. In: DENZIN, N; LINCOLN, T. Handbook of qualitative research. London: Sage, 2005.

WHITTINGTON, Richard. O que é estratégia. São Paulo: Pioneira Thompson Learning, 2002. 